\title{
The Missing Magmas of MOR
}

\author{
USTUNISIK, G.K. ${ }^{1,3}$, NIELSEN, R.L ${ }^{1,2}$ AND WALKER, D. ${ }^{4}$ \\ ${ }^{1}$ South Dakota School of Mines and Tech., Rapid City, SD \\ 57701, USA \\ (*correspondenceGokce.Ustunisik@sdsmt.edu) \\ ${ }^{2}$ CEOAS, Oregon State Univ., Corvallis, OR 97730, USA \\ ${ }^{3}$ Earth and Planetary Sciences, AMNH, New York, NY \\ 10024, USA \\ ${ }^{4}$ Earth and Environmental Sciences, LDEO of Columbia \\ University, Palisades, NY 10964-8000, USA
}

Lavas erupted at the mid-ocean ridge (MOR) have long been used as a means of understanding mantle processes. However, using that approach to understand the full range of mantle compositions requires that the magmas present in the mantle be represented in the array of materials erupted on the seafloor. Plagioclase ultraphyric basalts (PUBs) are a class of MOR lavas characterized by abundant (up to $40 \%$ ) anorthitic (An85-94) plagioclase megacrysts. No MOR lava has been demonstrated to be in equilibrium with such anorthitic plagioclase. However, such primitive melts are present as melt inclusions in plagioclase megacrysts [1]. Further, new data on depth of entrapment based on $\mathrm{CO}_{2}$ contents in plagioclasehosted inclusions indicate that many of the megacrysts formed at upper mantle pressures [2]

In an attempt to better understand the phase equilibria of plagioclase in these systems, we conducted a series of experiments at 0.5 and $1.0 \mathrm{GPa}$ on a modified MOR liquid to which anorthitic plagioclase and forsteritic olivine were added. Our results confirm those of Nekvasil [3] documenting the presence of a pseudoaziotrope, as first identified by Lindsley [4], in the anorthitic segment of the Ab-An pseudobinary. Our contribution is to confirm that aspects of the topology of the plagioclase loop are present in MOR magmas. Those characteristics have the effect of dropping the anorthitic end of the feldspar loop and lowering the solidus for upper mantle conditions. Magmas evolving under those conditions would evolve to higher $\mathrm{Ca} \#$ and lower $\mathrm{Mg} \#$ at pressures above $\sim 0.5$ GPa. As magmas rise, the aziotrope disappears, and the feldspar loop at the high An end rises. This would cause those magmas to undergo decompression crystallization which will prevent such liquids from ever being erupted on the seafloor as glasses. Therefore, the phase equilibria conditions responsible for the generation of the liquids in equilibrium with anorthitic megacrysts prevent those liquids from being sampled.

[1] Sours-Page et al. (1999) Cont. Min. Pet., 134,342-363. [2] Drignon et al. (2019) Geochem Geophys Geosyst., 20, 109199. [3] Nekvasil et al. (2015) Geo Res Lett, 42, 10573-10579 [4] Lindsley (1969) Geo Res Let., 18, 39-46. 